\title{
Validation of an hourly resolved global aerosol model in answer to solar electricity generation information needs
}

\author{
M. Schroedter-Homscheidt ${ }^{1}$ and A. Oumbe ${ }^{2, *}$ \\ ${ }^{1}$ German Aerospace Center (DLR), Earth Observation Center (EOC), 82234 Oberpfaffenhofen, Germany \\ ${ }^{2}$ Total New Energies, R\&D - Concentrated Solar Technologies, 2 place de Vosges - La Défense 5, 92400 Courbevoie, France \\ *formerly at: German Aerospace Center (DLR), Earth Observation Center (EOC), 82234 Oberpfaffenhofen, Germany
}

Correspondence to: M. Schroedter-Homscheidt (marion.schroedter-homscheidt@ dlr.de)

Received: 2 July 2012 - Published in Atmos. Chem. Phys. Discuss.: 11 December 2012

Revised: 24 February 2013 - Accepted: 10 March 2013 - Published: 10 April 2013

\begin{abstract}
Solar energy applications need global aerosol optical depth (AOD) information to derive historic surface solar irradiance databases from geostationary meteorological satellites reaching back to the 1980's. This paper validates the MATCH/DLR model originating in the climate community against AERONET ground measurements. Hourly or daily mean AOD model output is evaluated individually for all stations in Europe, Africa and the Middle East - an area highly interesting for solar energy applications being partly dominated by high aerosol loads. Overall, a bias of 0.02 and a root-mean-square error (RMSE) of 0.23 are found for daily mean AOD values, while the RMSE increases to 0.28 for hourly mean AOD values. Large differences between various regions and stations are found providing a feedback loop for the aerosol modelling community. The difference in using daily means versus hourly resolved modelling with respect to hourly resolved observations is evaluated. Nowadays stateof-the-art in solar resource assessment relies on monthly turbidity or AOD climatologies while at least hourly resolved irradiance time series are needed by the solar sector. Therefore, the contribution of higher temporally modelled AOD is evaluated.
\end{abstract}

\section{Introduction}

Accurate knowledge about the variable aerosol concentration and composition in an hourly or daily temporal resolution is needed for the surface solar irradiance quantification used as basis for yield assessments of solar energy systems. Proper solar irradiance estimates can be derived either from on-site measurements, satellites as, e.g., the Meteosat satellites going back to 1983 , or from numerical weather prediction modelling and reanalysis projects. On-site measurements only seldom exist as long-term time series and numerical weather prediction reanalysis projects mostly provide only coarse resolution information not suitable for the assessment of a single potential power plant location. Satellite-based methods provide a large temporal and spatial coverage with sufficient accuracy and represent the current state-of-the-art. They often rely on a cloud index method (e.g., Cano et al., 1986; Beyer et al., 1996; Rigollier et al., 2004; Schillings, 2004) making use of external aerosol databases as auxiliary input.

Atmospheric aerosol extinction typically reaches $30 \%$ of the incoming direct irradiance in most locations and can reach values up to $100 \%$ in strong pollution or dust events. Global irradiance is also affected by extinction, but with a typical range of only up to $10 \%$. Additionally, dust soiling on concentrating solar power mirrors or photovoltaic panels significantly decreases the performance of the system. Wittmann et al. (2008) discuss the interaction of atmospheric extinction with solar electricity generation reporting electricity production losses of $24 \%$ for a typical aerosol loaded day in Southern Spain. Due to aerosol variability, a pure interpolation between ground measurements (if existing at all in the 1980's and 90's) is inadequate, and dedicated aerosol observations from satellites with a broader spatial coverage are available only from 2000 onwards.

Typically, climatological monthly mean aerosol optical depth (AOD) in approx. $4 \times 5^{\circ}$ spatial resolution (e.g., Tegen et al., 1997; Kinne et al., 2003; Schmidt et al., 2006) are used. Due to larger shares of solar energy in the electricity 
supply system, increasing accuracy requirements for surface irradiances are frequently stated. Horizontal AOD correlation lengths below $200 \mathrm{~km}$ are found in ground, aircraft and space-based measurements (Anderson et al., 2003), and a significant variability in the range of hours to single days is typically observed in aerosol ground measurements. Therefore, the existing AOD datasets derived in the climate modelling community are no longer sufficient for this purpose.

Even if exact modelling of aerosol processes and sources remains an on-going research question, it is the objective of this paper to evaluate a chemistry transport model (CTM) representing the existing state-of-the-art with respect to information needs from the solar electricity generation sector. Such a CTM needs to fulfil the criteria of being applicable with reasonable processing effort on a global scale, including all relevant aerosols and especially a dust aerosol component, covering the time period from 1983 as the first year of Meteosat satellite observations onwards, providing at least an hourly temporal resolution, and dealing not only with particulate matter mass concentrations at ground level, but also with total column AOD suitable for the use in radiative transfer models. Therefore, the capabilities of the Model of Atmospheric Transport and Chemistry (MATCH, Collins et al., 2001) and the Dust Entrainment and Deposition model (DEAD, Zender et al., 2003) included in MATCH have been analysed. A special focus is laid on the region of the Meteosat satellites covering Europe, Africa, and the Middle East.

Existing model inter-comparison or validation studies typically focus on the comparison of global or regional mean values or they focus on annual or monthly means (e.g., Tegen et al., 1997; Chin et al., 2002; Takemura et al., 2002; Luo et al., 2003; Zender et al., 2003; Kinne et al., 2003, 2006; or Textor et al., 2006). Validation efforts on the daily and hourly scale are typically restricted to case studies (e.g., Morcrette et al., 2009; Santese et al., 2010; Spyrou et al., 2010) or analyse a few stations only which often have an extended instrumentation giving detailed insight into a specific physical process (e.g., Hand et al., 2004; Gong and Zhang, 2008; Heinold et al., 2009; Su et al., 2009).

MATCH has been included in several model comparisons with respect to global or regional mean values or annual or monthly means. Mahowald et al. (1997, 2002, 2003) evaluated the horizontal and vertical transport schemes, assessed the model versus the Barbados station record, and quantified inter-annual variability versus several AERONET stations. Kinne et al. (2006) included MATCH in the AEROCOM model comparison finding a general good agreement of total AOD, but less agreement among the contributing models in terms of absorption and, therefore, the aerosol type. Textor et al. (2006) assessed MATCH within the AEROCOM comparison dealing with aerosol type specific life cycles, while Huneeus et al. (2011) present the AEROCOM comparison at dusty AERONET sites. Nevertheless, an assessment of daily mean or hourly resolved AOD values on the level of all AERONET stations in a larger region is missing so far both for MATCH and other global models.

The paper does not aim at improving nowadays aerosol modelling by providing own modelling studies. Rather, the structure is motivated by solar energy needs and, therefore, provides assessments typically not found in existing aerosol model validation studies. It is assumed that this unconventional view will provide additional insight into strengths and weaknesses of nowadays global aerosol modelling and, therefore, helps to improve the modelling in the mid-term. The paper especially focuses on

- AOD instead of mass concentrations to allow the assessment of atmospheric extinction (different from the air quality community),

- dust aerosols allowing the evaluation of high solar potentials in Southern regions being dominated partly by large deserts (different from some parts of the air quality community),

- hourly AOD to follow the need for at least hourly resolved irradiance time series for power plant simulations (instead of monthly means in the climate community),

- daily AOD (instead of monthly means in the climate community) in order to quantify the value of hourly AOD modelling as the basis of daily mean generation, and compared to daily AOD assessments e.g., from MODIS satellite data as suggested by some solar energy experts,

- point-wise comparisons even for coarse resolution global model datasets reflecting the practice in the solar sector (instead of large area means used in several climate model validation studies),

- comparing obviously different datasets as an hourly model run versus a monthly mean dataset. This is motivated by the fact that using such datasets is the state-ofthe-art in many existing solar energy resource assessments and in order to quantify the impact created by using a higher resolved, but computationally expensive model, e.g., in operational NWP centres.

Section 2 describes all data used including the MATCH model version, the long-term dataset created and AERONET ground measurements. Section 3 discusses a suggested postprocessing with respect to overestimation in dust episodes. Section 4 provides overall validation results for daily and hourly mean AOD against the AERONET network and justifies the post-processing approach chosen, while Sect. 5 provides a station-wise and regionally resolved assessment. It also addresses the question of the need for hourly versus daily mean model output with respect to hourly observations. Section 6 discusses a comparison against an AOD climatology used in the SOLEMI irradiance database as an example 
for the current state-of-the-art in surface solar irradiance assessments, and finally Sect. 7 concludes the paper.

\section{Data}

\subsection{MATCH model long-term dataset}

The Model of Atmospheric Transport and Chemistry (MATCH, Collins et al., 2001; Fillmore, 2005; Rasch et al., 1997) is a three-dimensional global transport model describing an external aerosol mixture of several aerosol types. Tropospheric sulphate, sea salt and carbonaceous aerosols are treated with a constant lognormal aerosol size distribution, while the dust model distinguishes 4 dust bin sizes from $0.01-1,1-10,10-20,20-50 \mu \mathrm{m}$ effective particle radius and assumes a lognormal size distribution in each of the bins. Sea salt aerosols are treated only in the diagnosis mode without any transport. AOD is calculated separately for each aerosol type using optical extinction coefficients for each species following Kiehl et al. (2000) for sulphates and Haywood and Ramaswamy (1998) for sea salt and carbonaceous aerosols. Dust optical properties are calculated from Mie theory using the refractive index as provided by Patterson (1981).

MATCH includes emission databases for seasonal sulphur emissions at 0 and $100 \mathrm{~m}$ height for 1990 and 2005, monthly mean surface di-methyl sulphate (DMS) emissions, monthly mean biomass burning black and organic carbon fluxes, monthly mean natural organic carbon fluxes from terpene emissions, fossil fuel black and organic carbon surface fluxes and an explicit dust mobilisation scheme (DEAD). Anthropogenic sulphur emissions are described in the Global Emissions Inventory Activity (GEIA) dataset (Benkowitz et al., 1996; http://www.geiacenter.org) with extensions made by Smith et al. (2001) providing country-level sulphur dioxide emissions from the US Environmental Protection Agency (USEPA), the European Environment Agency (EEA), an inventory for the former Soviet Union region by Ryaboshapko et al. (1996) and Environment Canada. For Australia and New Zealand, emissions were taken from the 1985 GEIA 1B inventory (Scholtz et al., unpublished data). For the rest of Asia, Latin America, Africa and the Middle East, emissions are calculated from regional fuel consumption and fuel properties. Ship emissions are taken from IEA/OECD (1997), and industrial process emissions for developing regions follow the EDGAR database (Olivier et al., 1996). Biomass burning emissions from the EDGAR database are used, while emissions from traditional biomass combustion follow Streets and Waldhoff (1998). A seasonal dependence of emission rates reflecting the fossil fuel consumption as a function of weather conditions is included. The biomass burning emission's seasonality is estimated using regional fire data. Seasonal $\mathrm{SO}_{\mathrm{x}}$ emissions are provided in a $1^{\circ} \times 1^{\circ}$ resolution for the reference year 1990 and projected into the future years 2005, 2020, 2035, 2050, 2065, 2080 and 2095. Emissions at the surface $(0 \mathrm{~m}$ height $)$ from low-temperature burning are distinguished from $100 \mathrm{~m}$ injection height's sulphur as typical for factory or ship sources with high-temperature combustion. The emission database is interpolated linearly towards the actual date. Oceanic DMS concentrations are described in a monthly $1 \times 1^{\circ}$ climatology derived by Kettle et al. (1999). Black and organic carbon emission inventories are monthly climatologies based on Liousse et al. (1996) for biomass burning aerosols and Penner et al. (1993) for fossil fuel burning sources. The production of natural organics is assumed as $10 \%$ (Collins et al., 2001) of the total terpene emissions as described in Guenther et al. (1995). Vertical sea salt profiles are derived from $10 \mathrm{~m}$ wind speed after Blanchard and Woodcock (1980) and Fillmore (2005) in each time step.

Physical and chemical processes include a flux-form Semi-Lagrange advection description (Rasch and Lawrence, 1998), convective and turbulent transport, dry (Collins et al., 2001) and wet deposition (Rasch and Kristjansson, 1998), cloud-aerosol interactions, the sulphur cycle (Barth et al., 2000; Rasch et al., 2000), ageing, particle size transformation and hygroscopic growth.

The DEAD (Mineral Dust Entrainment and Deposition) model describes dust emission produced by the saltation process as a function of surface layer wind speed and a spatially varied erodibility, which is reduced in case of seasonal vegetation and modified according to the clay fraction in the underlying ground. The threshold friction velocity is described as a function of particle density, gravitational acceleration, particle diameter, kinematic viscosity of the air, and air density following wind tunnel experiments (Marticorena and Bergametti, 1995). A surface erodibility factor is used comparing local altitudes and identifying regional minima in altitude within $10 \times 10^{\circ}$ boxes resulting in a map of historical hydrological basins in the Saharan and Sahel region (Ginoux et al., 2001). Aerosols are mixed into the lowest model sigma coordinate level. Dry deposition of dust particles is modelled through gravitational settling and turbulent mix-out, while wet deposition is modelled as in-cloud and below-cloud scavenging.

MATCH is an offline transport model using NCEP's (National Centre of Environmental Prediction) operational or reanalysis meteorological fields as meteorological driver every $6 \mathrm{~h}$ which are interpolated linearly towards the actual time step. The MATCH/DLR v4_dlr1.0 version has been obtained from NCAR (National Centre for Atmospheric Research) and modified for data handling purposes mainly. It is not the purpose of this work to improve the modelling inside MATCH, but to take it as an example of a state-of-theart global model and assess it from the solar sector's pointof-view. Additionally, it has been adapted to provide AOD output at other wavelengths than the standard $550 \mathrm{~nm}$ and Angstroem coefficients. To cover the period of the Meteosat satellite observations a long-term dataset has been generated: This dataset consists of hourly values for the period 1 January 
1983 to 31 December 2009. It uses the NCEP/NCAR reanalysis (http://rda.ucar.edu/datasets/ds090.0/) with a T62L28 resolution input resulting in an approx. $1.9^{\circ}$ reduced Gaussian grid. The temporal resolution is set to $30 \mathrm{~min}$ and even 2 min in the sulphur chemistry sub-cycle. Besides the total AOD at 400, 550 and $800 \mathrm{~nm}$ wavelengths, the AOD for all aerosol types and size bins (in the case of dust) is stored separately. The Angstroem coefficient based on 400 and $800 \mathrm{~nm}$ is given additionally.

\subsection{AERONET ground measurements}

AERONET's (AErosol RObotic NETwork, http://aeronet. gsfc.nasa.gov) ground-based sun photometer measurements (Holben et al., 1998) are used for AOD validations at $550 \mathrm{~nm}$. In this study, hourly and daily means of AERONET version 2 , level 2 data are applied. They include a manual cloud checking procedure. The overall uncertainty of AERONET AOD values in cloud-free conditions is \pm 0.01 for wavelengths down to $440 \mathrm{~nm}$. AERONET is a global network with approximately 600 stations, while this study is based on 168 stations in Europe, Africa and the Middle East being located in the Meteosat field-of-view.

It has to be noted that validations based on AERONET data consist of clear-sky cases only. This well-known restriction is not blocking in our case as the solar sector is interested in aerosol information only for the clear-sky case as in cloudy conditions the clouds are the dominating factor.

Aerosols are of special importance for concentrating solar technologies which are using direct irradiation as their resource. These technologies require large annual sums of direct irradiation which are typically only reached in the solar belt. This area is also affected by larger amounts of dust aerosols from desert regions - reducing the solar irradiance through extinction as well as the reflectance of mirrors in the power plant through soiling. Therefore, the treatment of dust mobilisation is of special interest and we focus on an evaluation for the year 2004 with, due to the United Arab Emirates Aerosol Experiment (UAE ${ }^{2}$, Reid et al., 2005), increased AERONET data availability.

Stations with less than 40 observation days in 2004 have been excluded, leaving 64 stations for further evaluations (Fig. 1). For hourly resolved comparisons a minimum of 480 observation hours ( 40 days times $12 \mathrm{~h}$ ) is required, reducing the number of stations in hourly validations to 55 . Hourly resolved MATCH/DLR output between 01:00 and 24:00 UTC is averaged to obtain daily means. Overall a number of 9899 coincidences is analysed in the daily mean dataset and 64795 coincidences are found in the hourly dataset.

\section{Post-processing of MATCH/DLR}

A sudden and strong increase of MATCH/DLR AOD is sometimes found in the dust aerosol component motivating

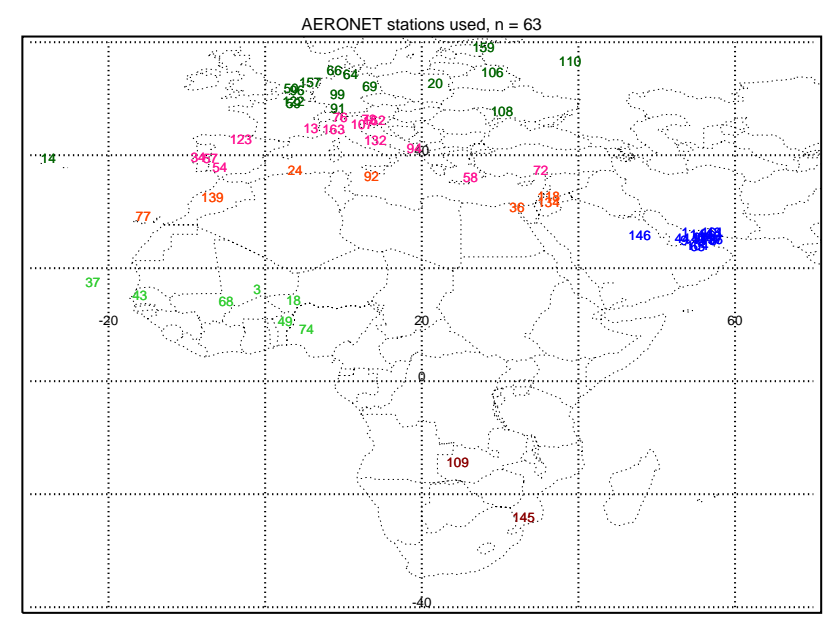

Fig. 1. Location of AERONET stations - station numbers represent an alphabetically ordered list of AERONET stations evaluated. The colour coding represents different regional subsets: Northern and Central Europe (dark green), Southern Europe (pink), Northern Africa (orange-red), Arabian Peninsula (blue), Central Africa (light green), and Southern Africa (dark red).

the hypothesis of an overestimation in such events. Typically, AERONET observations are missing in these situations. Visual interpretation in Meteosat Second Generation's SEVIRI (Spinning Enhanced Visible and Infrared Imager) colour composite imagery reveals that such cases are characterised typically by a cloud system with additional dust uptake. AERONET typically cannot distinguish clouds from dust in such mixed cloud/dust cases and observations are removed from the level 2 database in the cloud clearing scheme. Therefore, AERONET generally can neither support nor reject the hypothesis of overestimating peaks in MATCH/DLR in most of these cases. Additionally, one has to be aware about the tendency in AERONET data to flag strong dust events as cloudy and to remove this data. Nevertheless, there are some cases with existing AERONET observations supporting the hypothesis of the MATCH/DLR overestimation in strong dust events - Figs. 2 and 3 provide examples for the stations Lampedusa and Forth Crete. Also, AERONET measurements in cloud-free conditions after such events indicate that the dust load is too high.

Having in mind that the solar sector is interested especially in the dust modelling, a spike post processing scheme has been developed by visual interpretation and validation against AERONET based on data in 2003. Suspicious dust events are marked if either a strong temporal gradient occurs in daily means

$\mathrm{AOD}_{\text {dust }, i+1}-\mathrm{AOD}_{\text {dust }, i}>0.7$

with $i=i$-th day in the time series 

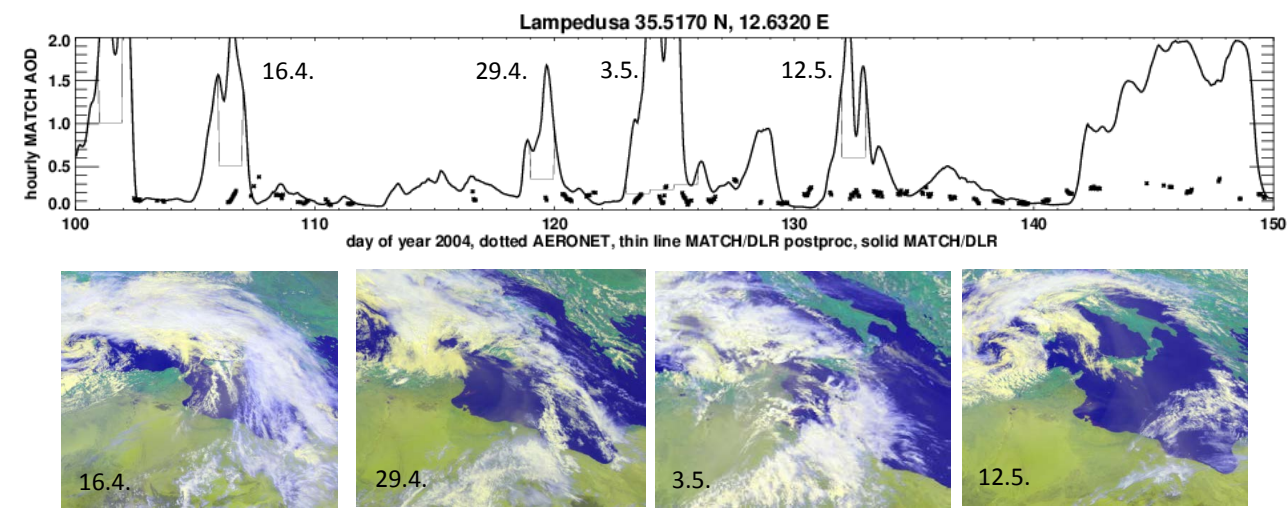

Fig. 2. Time series of daily mean AOD from AERONET (dotted), MATCH/DLR without post-processing (solid), and MATCH/DLR with post-processing (thin line) at the station Lampedusa and for 2004. Four dates with applied post-processing in cloudy cases are marked and given as colour composites based on 12:00 UTC MSG SEVIRI satellite imagery suitable for visual interpretation (copyright MSG imagery EUMETSAT/DLR).

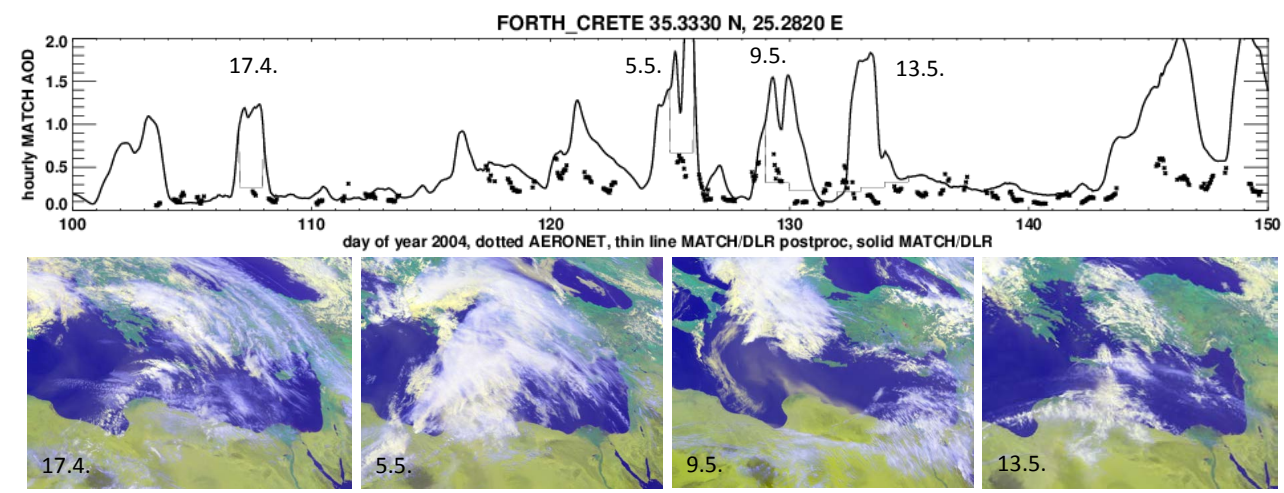

Fig. 3. Time series of daily mean AOD from AERONET (dotted), MATCH/DLR without post-processing (solid), and MATCH/DLR with post-processing (thin line) at the station Forth_Crete and for 2004. Four dates with applied post-processing in cloudy cases are marked and given as colour composites based on 12:00 UTC MSG SEVIRI satellite imagery suitable for visual interpretation (copyright MSG imagery EUMETSAT/DLR).

or the AOD value is large and also dominated strongly by dust

$\mathrm{AOD}_{\text {dust }, i} / \mathrm{AOD}_{\text {total }, i}>0.95$ and $\mathrm{AOD}_{\text {total }, i}>1.0$

As typically large scale dust events last longer than one day, all days following a detected dust peak on a day $j$ with

$\mathrm{AOD}_{\text {dust }, j+n}-\mathrm{AOD}_{\text {dust }, j}>0.3$

with $n=1,2,3, \ldots$ as long as the above criterion is met

are also marked as suspicious dust cases. Flagged values are eliminated from the time series and replaced by a linear interpolation between the last and the first "good" data point around the gap. Additionally, a low pass filter with a length of 3 days is applied to smooth the time series.

Currently, the physical background of these peak-like overestimations is not known and needs further evaluation in the aerosol science community. Probably, the physical explanation includes different processes acting in different cases.
It is beyond this study to investigate this. It has to be noted that this correction practically replaces dust AOD peaks by background conditions instead of keeping the dust peak and changing its value. For aerosol research this is not satisfying as real dust events are probably underestimated and the cloud-aerosol interaction in these cloudy situations is not treated physically. But for the solar sector the correction of AOD values during the event is of minor interest as these cases are cloudy and the direct irradiance will be low anyhow. For this application, too large values in the cloud-free period after this cloud-aerosol event are critical. Therefore, the replacement of AOD values by a linear interpolation is appropriate for this sector, even if it bears the risk to underestimate by setting the value to a background or low aerosol situation. The validation (next section) confirms the usefulness of such an empirical post-processing for the solar sector being interested in the AOD accuracy in clear-sky cases mainly and only indirectly being interested in model improvements. 

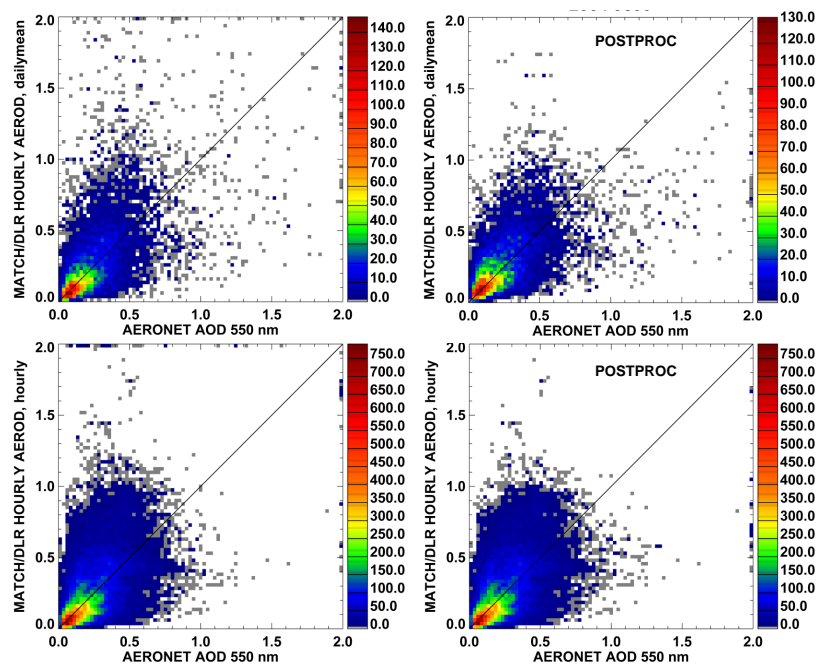

Fig. 4. Two-dimensional histograms of MATCH/DLR daily mean AOD vs. AERONET daily mean AOD (upper panels) and MATCH/DLR hourly AOD vs. AERONET hourly mean AOD (lower panels) for 2004. Left-hand panels include all coincidences before the spike post-processing, while right-hand panels show results after the post-processing. Values above 2.0 are truncated to the maximum values. The colour bar indicates the number of occurrences in each bin of the AERONET and MATCH/DLR AOD axes.

\section{Validation - overall assessment}

Figure 4 shows the validation of all data with and without spike post-processing (PP) for daily and hourly means in order to justify the spike post-processing development and use. Due to the large number of data points two-dimensional histograms have been chosen instead of scatterograms. Values above an AOD of 2.0 have been accumulated in the greater or equal 2.0 bin visible on the axes. A second assessment has been made for the year 2005 resulting in similar findings with respect to the post-processing. Here we report the results for 2004.

For daily means after the post-processing a good agreement within 0.1 can be observed for a majority of all cases. Below the AOD of 0.4 a strong linear relation is found, but for larger AOD values a remarkable scatter is found as well. The overall bias is 0.02 with a root-mean-square-error (RMSE) of 0.23 and a Pearson correlation coefficient $r=$ 0.54 . For hourly data and after applying the post-processing, an overall bias of 0.03 is found together with a RMSE of 0.28 and a Pearson correlation coefficient $r=0.45$. It has to be noted that the existing scatter in high values above an AOD of 2.0 is not directly visible in this figure as all data equal or above 2.0 is collected in the correspondent histogram bin being marked on the axes.

The MATCH/DLR model without post-processing tends to underestimate AERONET AOD less than 0.3 and overestimates data higher than 0.3 frequently. For daily mean values, the post-processing is able to correct this underestimation in the lower AOD by replacing large AOD values in peak situations by lower values in the gap filling interpolation. Large overestimations with MATCH/DLR AOD values above 1.0 can also be corrected by the post-processing. Both the correction of underestimated small AOD and overestimated large AOD values supports the hypothesis, that the dust uptake in MATCH/DLR is too strong in the mixed cloud/aerosol cases. Nevertheless, there are a number of cases with large AERONET/AOD values above 1.0 which are not found in the MATCH/DLR dataset and the post-processing scheme also over-corrects some daily mean AOD values larger than 1.0 which are found around the bisecting line in the daily mean statistics.

Both bias and RMSE decrease from 0.04 and 0.26 (without post-processing) to 0.02 and 0.23 for daily means and from 0.05 and 0.32 to 0.03 and 0.28 for hourly means if the postprocessing is used. In the overall statistics of daily means the post-processing effect is only small. This is reasonable, as these strong dust peaks occur only in a small number compared to the overall number of coincidences. Additionally, they are also frequently hidden through the automatic cloudclearing in AERONET or to the overlap of a both partially cloudy and aerosol situations resulting in no coincidences with AERONET in these cases. Nevertheless, if stations are evaluated separately, a significant improvement can be seen for several stations (Fig. 5).

Figure 5 and several following figures present target plots following ideas as introduced by Jolliff et al. (2009) and currently being widely adapted in the air quality community. It sets bias and centred root-mean-square-errors (CRMSE) in relation to each other. The CRMSE is the standard-deviation of the differences between the reference and the modelled AOD dataset. A movement towards the centre of this plot can be interpreted as an overall improvement in RMSE. In Central Europe (dark green) only minor changes are observed for most stations, while some stations change their position from the right-hand side to the left-hand side in the plot. This indicates that the CRMSE remains the same, but the modelled amplitude as described by the standard deviation $\sigma_{\text {mod }}$ of all modelled values is less than the observed amplitude at the station (as described by the standard deviation $\sigma_{\mathrm{obs}}$ of all observed values). This results in a change of sign in the difference $\sigma_{\text {mod }}-\sigma_{\text {obs }}$ resulting in a change of sign on the horizontal axis. It reflects the replacement of AOD variations in dust peaks by the less varying linear interpolation in the postprocessing. Nevertheless, in those stations the overall RMSE is not changed and especially not made worse by the postprocessing. A strong RMSE reduction is mainly found for the blue and orange-red marked stations representing the Arabic Peninsula and Northern Africa with their frequent dust events. Stations in Southern Africa (dark red) and Southern Europe (pink) are either not affected by the post-processing or switch their sign on the horizontal axis as described before. Most stations in Central Africa (light green) are only 


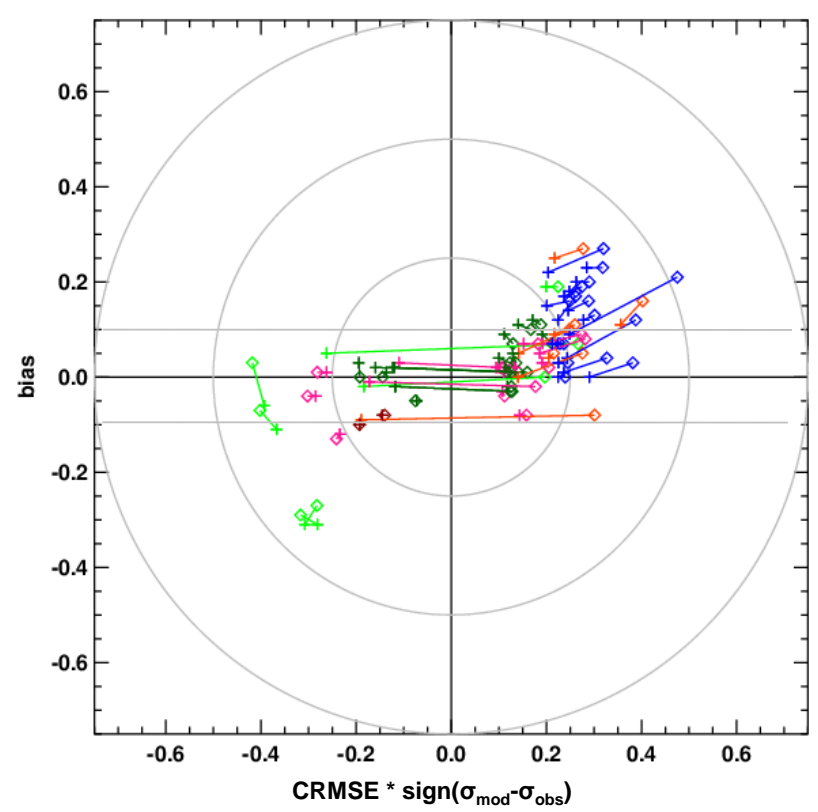

Fig. 5. Target plot for daily mean AOD values evaluated at AERONET stations. Colours are the same as in Fig. 1. Diamonds represent results obtained without post-processing, while crosses show results after the post-processing scheme.

slightly affected by the post-processing with the exception of two stations Dakar and IER-Cinzana showing the sign switch. Overall, it can be concluded that the post-processing is helpful in clear-sky conditions for the dust emission regions, while it does not harm in other regions. Therefore, the replacement of dust events by background values is justified in our case. In the following sections a station-wise validation sorted in different regions is given with a more extensive discussion of individual stations.

There is no dependency of validation results on station height or time of the day for the region shown, while for Asia (not further discussed here), a decrease of bias and RMSE is found in morning and afternoon hours.

In the following chapters, this empirical post-processing is used in all statistics. Figure 6 provides bias, RMSE and correlation coefficients for all stations separately while the following sections provide a denser discussion of some solar energy specific aspects with the help of target plots. Only stations with a satisfying number of coincidences (as defined in Sect. 2.1) both in the hourly and daily validation are included in Fig. 6. A detailed discussion of station results with respect to biases and RMSE is given in the next sections.

With respect to linear correlation coefficients, it has to be noted that several stations show even a negative correlation in hourly values as Lille, ISDGM_CNR, Venise and Mussafa having peaks in the model when the observations are low and vice versa. For Venise, there might be also a temporal phase error, as several peaks in the model occur 1-2 days later than in observations.

\section{Regional validation}

\subsection{Daily mean AOD values}

This section focuses on the validation of daily mean AOD at all AERONET stations individually. Summarising visualisation with the help of target plots following Jolliff et al. (2009) is provided in Fig. 7 with the colour coding for AERONET stations in different regions as introduced in Fig. 1.

In Europe (dark green), the bias at most stations remains below 0.1 , reaching values below \pm 0.03 in Dunkerque, Fontainebleau, Hamburg, Helgoland, Lille, Mainz, Moscow_MSU_MO, Palaiseau and The Hague. Only IFT-Leipzig and Moldova show higher values with 0.12 and 0.11 , respectively. RMSE is found to be in a range from 0.09 at the Azores to 0.21 in Belsk and IFT-Leipzig. Pearson correlation coefficients are always greater than 0.2 and reach typically values around 0.4. Both amplitude over- and underestimations occur, as seen in approximately half of the stations being on the positive and the negative side of the horizontal axis in Fig. 7.

In Southern Europe (pink) also the bias remains below 0.1 with exception of an underestimation of -0.12 in Ispra (station no. 76). Venise shows a strong underestimation of AOD values above 0.5 even if the bias remains low at 0.01 . There is no clear finding with respect to the modelled amplitude, about half of the stations in Southern Europe have a higher amplitude than observed, while the other half has a smaller amplitude than observed.

Still after the post-processing, within the Mediterranean strong overestimations with AOD values up to 1.8 are found in Lampedusa (bias 0.11), Blida (bias 0.04), and Forth_Crete (bias 0.07). For Forth_Crete and Blida, some of these overestimations can be allocated to strong dust events if using the criterion of $\mathrm{AOD}(1020 \mathrm{~nm})$ higher or equal than 0.3 and an Angstroem parameter derived from 440 and $870 \mathrm{~nm}$ lower or equal than 0.6 (Dubovik et al., 2002) for AERONET measurements. Nevertheless, this is not the case for Lampedusa. It remains the question how often such events occur even after the post-processing. In order to investigate the frequency of dust events in the Mediterranean with a higher risk of overestimation by the model, the Dubovik criterion is used for all AERONET stations. The stations in Southern France and Italy observe between 1 and 5 dust days and 6 cases are found in Palencia in Northern Spain. For the South of the Iberian Peninsula 10 cases are observed in Cabo da Roca and Evora, while 20 cases occur in El Arenosillo. Blida is affected by strong dust occurrence on 33 days, Lampedusa has 6 cases, Sede Boker shows 20 cases, Nes Ziona 17, and Forth-Crete 15 cases. It should be noted that the Dubovik criterion is sensitive only to strong dust cases, but it gives a first estimate 


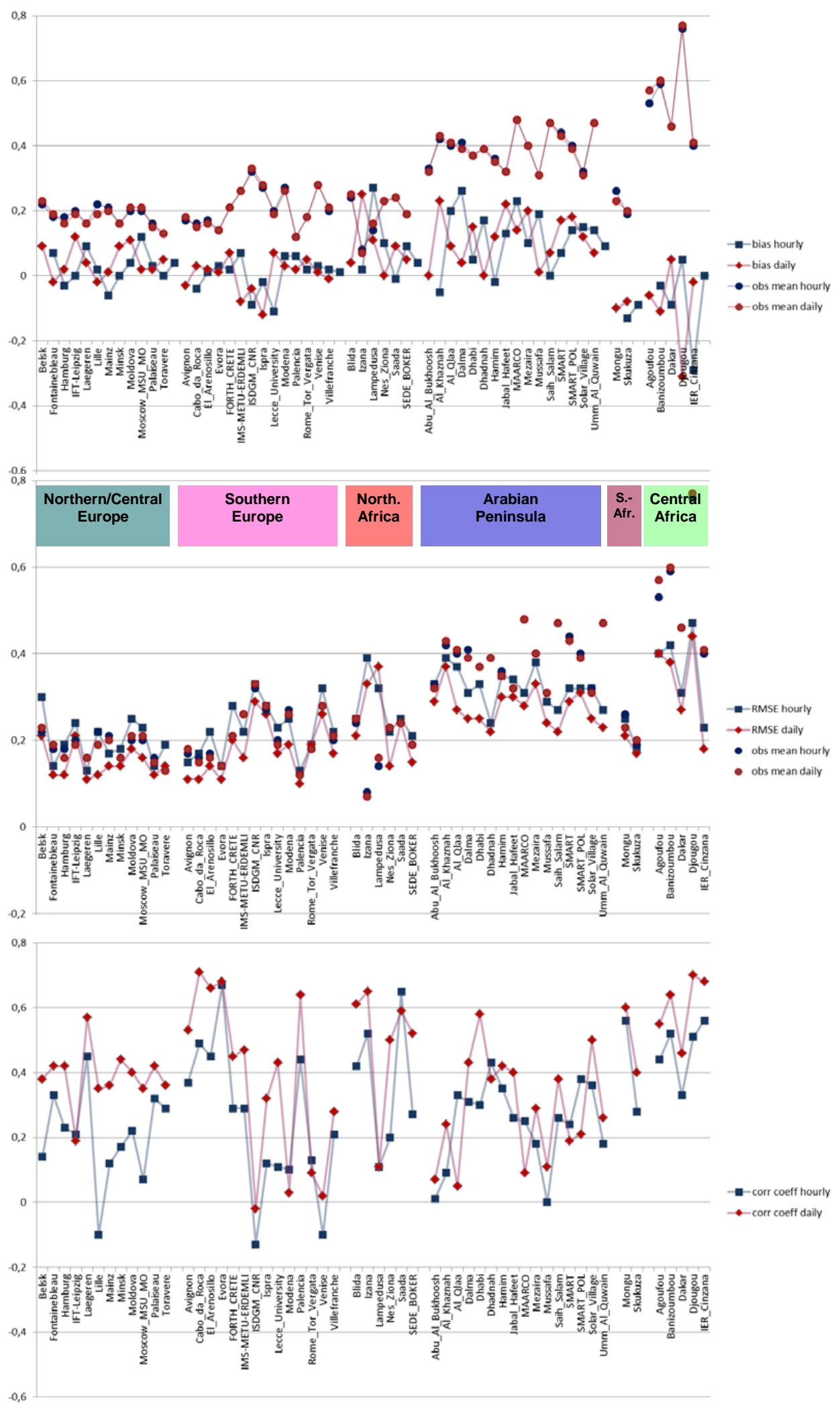

Fig. 6. Bias, RMSE, and correlation coefficients for daily mean (diamond) and hourly (square) AOD together with mean AOD values (obs) and being evaluated at AERONET stations. 

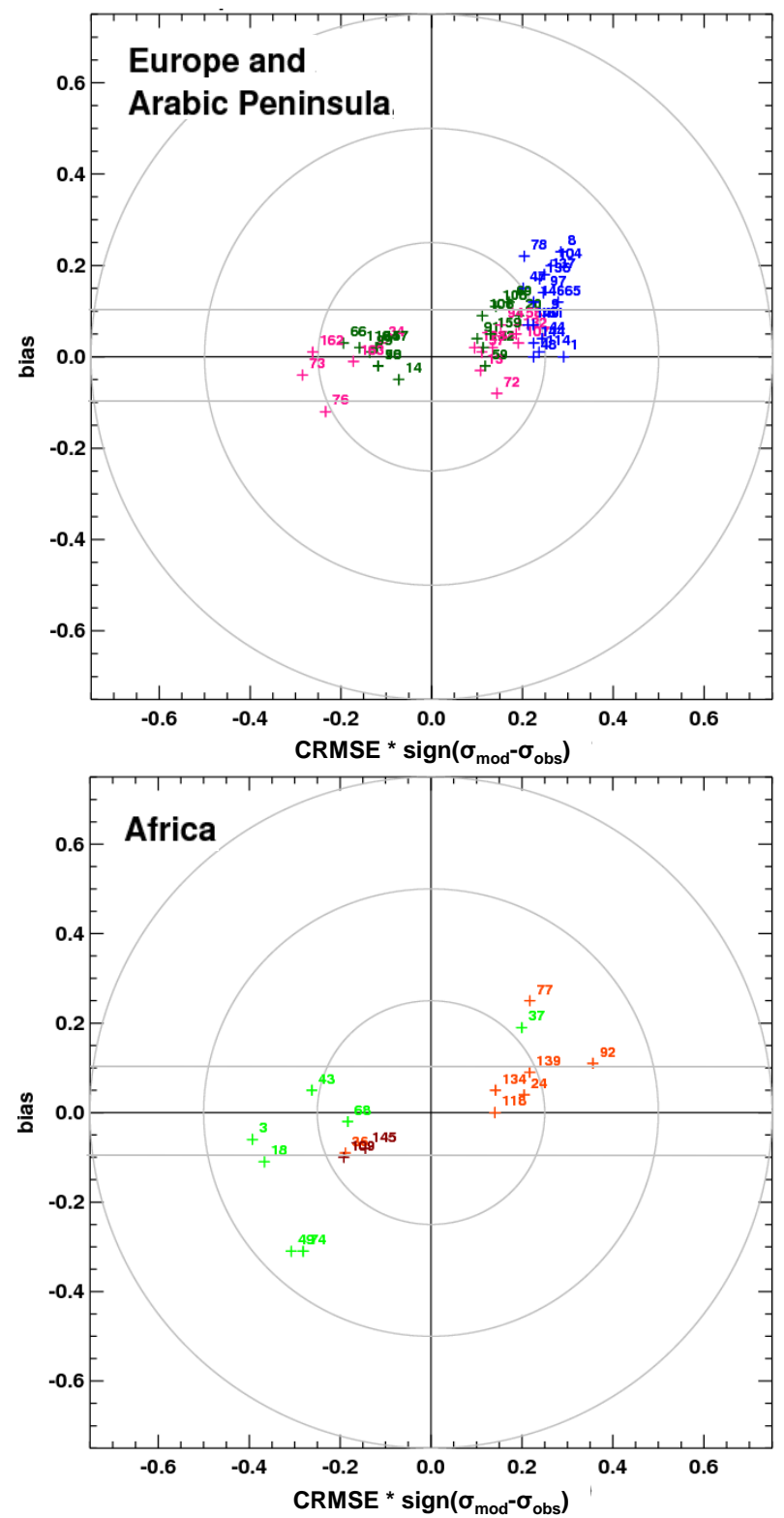

Fig. 7. Target plots for daily mean AOD values evaluated at AERONET stations. Colours and station numbers are the same as in Fig. 1.

about the frequency of occurrence of this potential modelling error.

The Arabian Peninsula shows generally a continuous positive bias at all stations with some strong overestimations with biases up to 0.23 and RMSE up to 0.37 in Al_Khaznah (station no. 8). A bias above 0.1 is also found at Dhabi, Hamim, Jabal Hafeet, MAARCO, Mezaira, SMART, SMART_POL and Solar Village (9 out of 17 stations in this region). Other stations, e.g., in the Strait of Hormuz (Abu Al Bukhoosh, Dalma, Dhadnah, Mussafa, Saih Salam, Sir Bu Nuair, and Umm Al Quwain) show a smaller bias between 0.0 and 0.07.
Generally, the RMSE ranges at high values between 0.22 and 0.37 and the amplitude of modelled values is always larger than the observed amplitude. It can be speculated that even after the correction of strong peaks in the post-processing scheme, the medium range AOD values still carry the signal of a too strong dust mobilisation which is kept trough the transport scheme.

Strongly overestimating stations are mostly located close to the border between the United Arab Emirates and Oman. Dust events affecting these stations and causing these overestimation in 2004 are mostly dominated by emission sources in Oman and the South of Saudi-Arabia. Contrary to Forth Crete and Lampedusa, the overestimations at these stations are not caused by long-range transported dust events, but by rather nearby local emissions. Generally, it is not clear if wrong spatial emission regions, a too strong emission at correct locations or an ineffective dry deposition scheme results in this wide overestimation and general scatter in this region.

AERONET stations in Northern Africa (orange-red) show a positive bias with the exception of Cairo_University ( -0.09 , station no. 36) and Nes_Ziona (0.0). A large positive bias of 0.25 exceeding the observations mean of 0.07 is found in Izana and the overall station pattern shows similarities to the results on the Arabian Peninsula. Typically, the modelled amplitude is larger than in the observations, with exception of Cairo_University.

AERONET stations south of the Sahara region (light green) are affected by dust outbreaks, but also by biomass burning as another important aerosol source. Generally, all Central African and South African stations with exception of Capo Verde show larger amplitudes in observed values than modelled resulting in negative values on the horizontal axis. A dedicated overestimating branch as on the Arabian Peninsula cannot be seen. Only Capo Verde (station no. 37 ) has a large positive bias of 0.19 resulting from overestimations of AOD observations around 0.5. Especially Djougou, Ilorin and Banizoumbou have strong negative biases of $-0.31,-0.31$ and -0.11 , respectively. This results from a general underestimation of AERONET observations above 0.7 at these stations. This holds also for the dust cases selected by the Dubovik criterion at these stations. This remarkable and general difference between the African and the Arabian stations indicates that strong dust overestimations in the MATCH/DLR dataset seem to be a regional issue for the Arabian Peninsula and the Middle East. This may point towards the erodibility databases as the most relevant factor for improvement instead of a general error in modelling e.g., of the dry deposition or the dust mobilisation. On the other hand, it is not clear without any deeper analysis if those air masses reaching the AERONET stations south of the Sahara have been altered by wet deposition which may overlay a possible general error in modelling in the dry deposition scheme. According to the AERONET site description the dust plumes observed in Ilorin typically originate 
from the Bodele Depression in the Chad Basin, a well-known strong emission source. This further strengthens the hypothesis of an underestimation of the surface erodibility of this region in MATCH/DLR. Mongu and Skukuza as South African stations show a underestimation with biases of -0.1 and -0.08 , but this cannot be explained by dust cases according to the Dubovnik criterion, which supports the hypothesis, that biomass burning as the other regionally important source causes this underestimation.

\subsection{Hourly mean AOD values}

As there is a need for a globally available database, the spatial resolution cannot be reduced to a 10 or $50 \mathrm{~km}$ horizontal grid due to computational constraints. Nevertheless, an increase in the temporal resolution from monthly means to daily or hourly values is requested by solar energy experts. There has been the attempt to provide higher resolved aerosol information based on daily satellite observations e.g., from MODIS or MISR. A combination of satellite instruments can provide at its best an estimate of the daily mean generated from two or more cloud-free observations, but even this is not possible in many regions of the world. Based on the variability seen in AERONET measurements hourly resolved aerosol information has been required as well, but it is not known if nowadays aerosol modelling is capable to provide sufficient accuracy for an hourly dataset.

Therefore, this section deals with the performance reached if the same model is run with approx. $1.9^{\circ}$ spatial resolution in an hourly resolution in order to derive daily mean values, and to compare them against hourly mean AOD ground measurements for each hour. Figure 8 provides the comparison of daily means (diamonds) and hourly AOD (crosses) with respect to hourly mean observations. For hourly variable values, Fig. 8 reveals a larger scatter for most stations resulting in an increase in the RMSE in the range of typically 0.03 to 0.1 in most regions. Several European stations (dark green and pink) show larger modelled amplitudes in hourly means than the observations shifting from the left-hand side to the right-hand side of the plot. For African stations, the differences in comparing daily mean and hourly values are much smaller than in Europe - largest differences are found at the Northern African stations.

\section{Comparison against an aerosol climatology used as state-of-the-art}

Currently, the SOLEMI database (Schillings et al., 2004) for long-term global and direct irradiance time series is based on the GACP (NASA/GISS, Tegen et al., 1997) dataset. Based on chemical transport modelling AOD is provided as monthly means for sea salt, soil dust, sulfate, carbonaceous aerosols and black carbon. Its spatial resolution is $4 \times 5^{\circ}$ on a global scale. The monthly means are meant as represen-
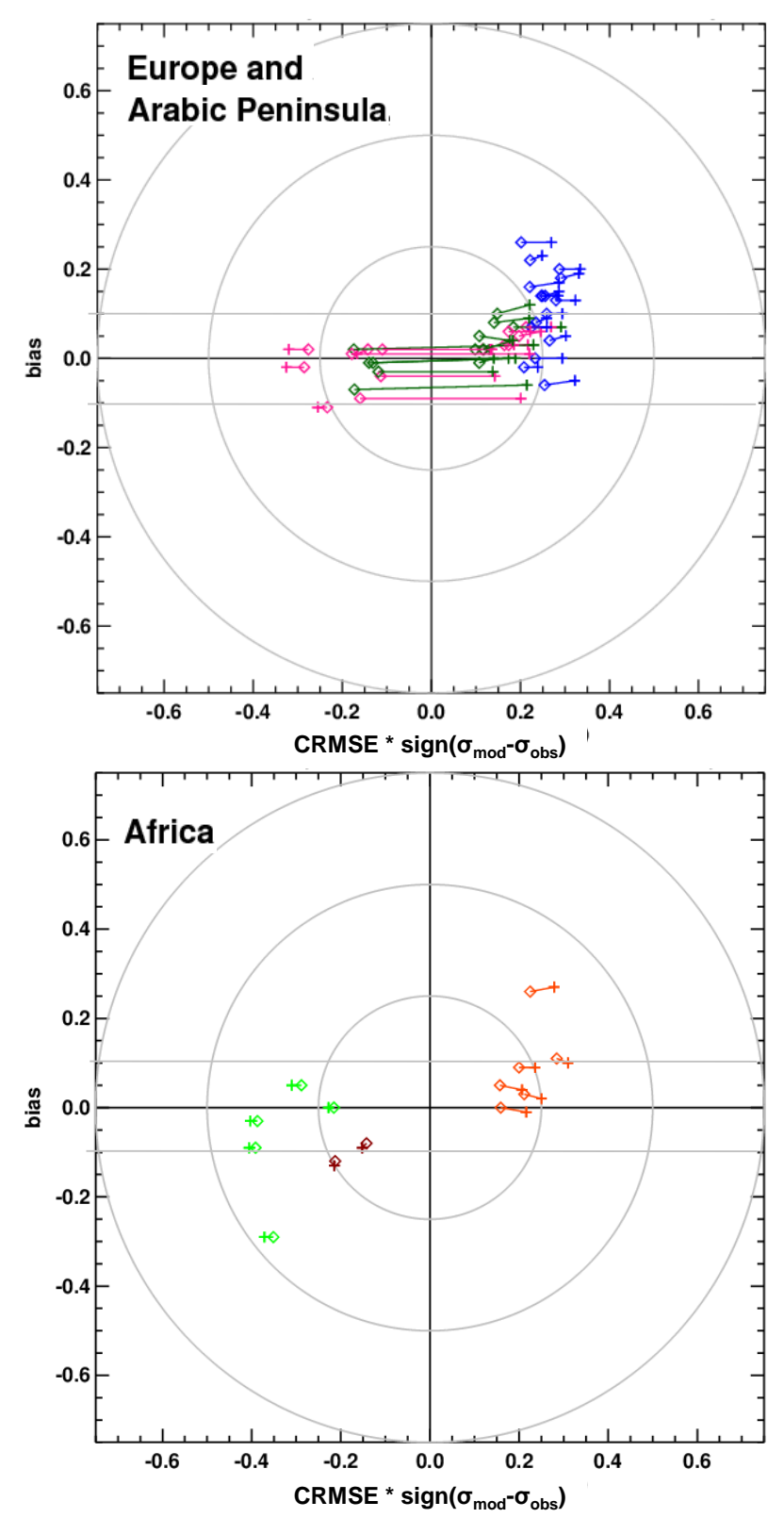

Fig. 8. Target plots for daily mean values used in all hours (diamond) and hourly modelled (crosses) AOD values evaluated at AERONET stations. Colours are the same as in Fig. 1.

tative datasets applicable for all calendar years. Obviously, this temporal and spatial resolution is rather coarse. Using a global scale MATCH/DLR with a daily or even hourly temporal resolution and with a spatial resolution of 1.9 degrees holds the potential to improve this situation. Therefore, a comparison between validation results against AERONET measurements is performed for the MATCH/DLR daily mean and the GACP dataset.

The GACP dataset shows large underestimations with biases up to -0.5 in Central Africa (light green), which are 

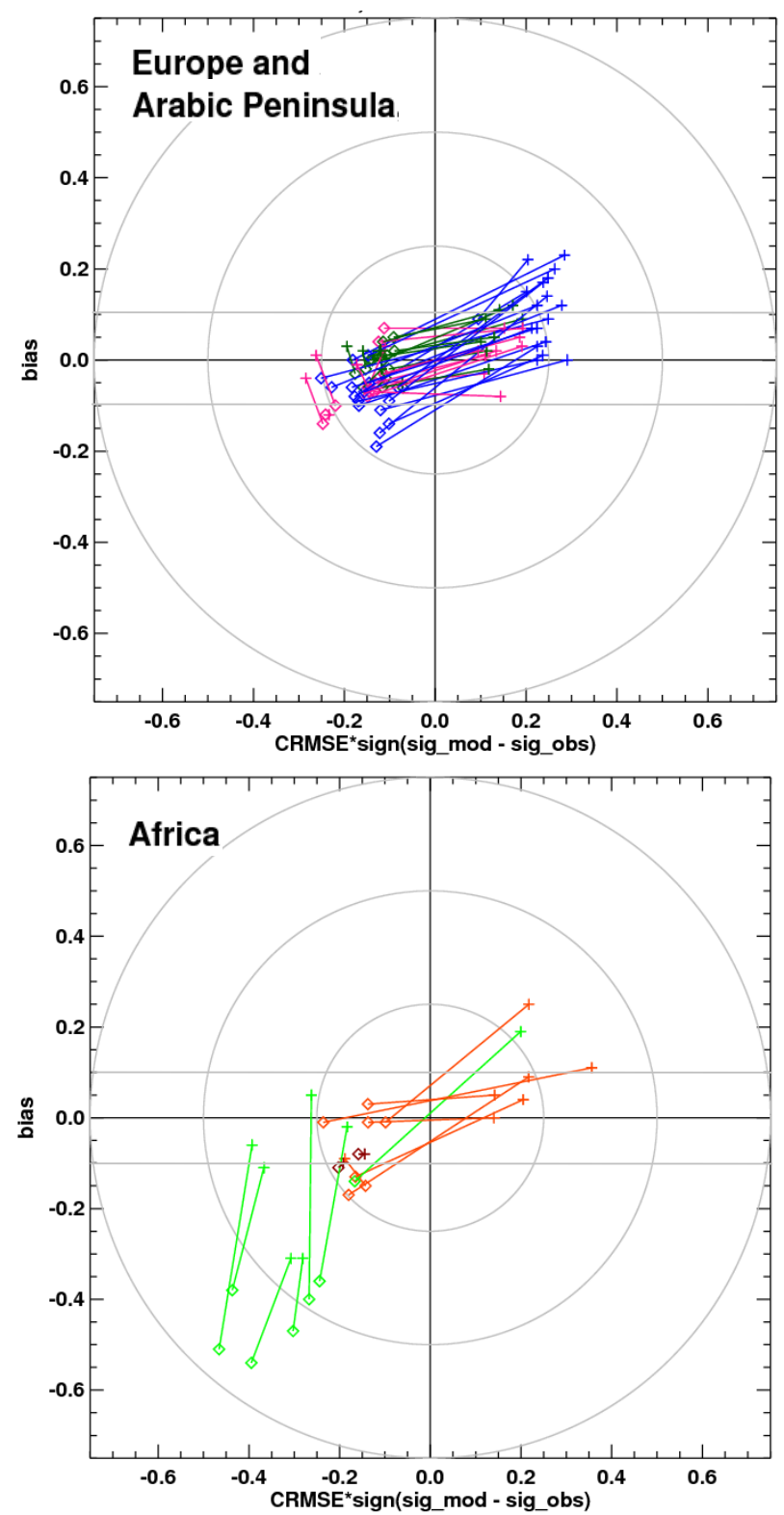

Fig. 9. Target plots for GACP (diamond) and daily mean MATCH/DLR (cross) AOD values evaluated at AERONET stations. Colours are the same as in Fig. 1.

smaller in the MATCH/DLR dataset (Fig. 9). Negative biases in Venise and ISDGM_CNR (Italy) are corrected by MATCH/DLR. In the Arabian Peninsula (blue), strong negative biases tend to become strong positive biases and the amplitude changes from being too small in the GACP climatology to being too large in the MATCH/DLR. Small negative biases between 0 and -0.1 remain small, but become positive between 0 and 0.1 at several stations. And finally, there are two stations Al_Khaznah and Mezaira which have a negligible bias in GACP and get a large bias in the MATCH/DLR dataset. Overall, the performance on the Ara- bian Peninsula for both datasets needs improvement. Northern African stations (orange-red) show a similar behaviour. Izana and Lampedusa are getting a large positive bias in the MATCH/DLR dataset while it is close to zero in the GACP. On the other hand, Blida, Cairo, Nes_Ziona, and Saada are better within MATCH/DLR. The major difference is found in the correlation coefficients which are much larger for the MATCH/DLR dataset for most stations with exception of some stations at the Arabian Peninsula (Fig. 10). Exceptions are the stations Dhadnah, Hamim, Maarco, Mussafa, Sir Bu Nuair, SMART and SMART_POL. They are all located on the Arabian Peninsula close to dust sources. For Dhadnah, Hamim and Mussafa, several dust events are well met, but others are strongly under- or overestimated in time series of daily values. Maarco, Sir Bu Nuair, SMART, and SMART_POL are having less than 60 coincidence days in the year 2004 and being close to dust sources, the results are driven by a small number of events only. Nevertheless, also here some events are well met, while others are over- or underestimated. Altogether, this might point into the direction of wrong thresholds for the minimum wind speed required for the start of dust mobilisation in this region.

\section{$7 \quad$ Summary and conclusions}

This paper focuses on the accuracy assessment of daily and hourly resolved state-of-the-art global aerosol modelling with respect to solar energy needs. It uses the MATCH/DLR model version v4_dlr1.0 for this purpose and provides an overview on aerosol physics and chemistry, the emission databases and the transport scheme implemented in this model. A dataset for 1983 to 2009 in hourly resolution on a $1.9^{\circ}$ reduced Gaussian grid has been created as auxiliary dataset for long-term satellite-based solar irradiance databases in order to replace monthly mean databases on a $4 \times 5^{\circ}$ grid used so far. This dataset is validated against AERONET data in Europe, Africa and the Middle East which implies a validation in clear-sky conditions. This also fulfils the needs of solar energy for accurate AOD in clearsky situations, while aerosol loads in cloudy conditions are not interesting for this purpose. The focus is laid on the validation of daily and hourly means while most existing studies deal either with monthly means only or focus on a few stations only.

For the year 2004, a total number of 9899 coincidences for daily means and 64795 coincidences for hourly means from 64 stations are analysed. The overall bias is 0.02 with a RMSE of 0.23 and a Pearson correlation coefficient $r=0.54$ for daily means. Hourly means reveal a bias of 0.03 , a RMSE of 0.28 and a correlation coefficient $r=0.45$.

A remarkable scatter can be observed especially for AOD values above 0.4 and is analysed deeper. For the western Mediterranean region (Spain, Portugal) a good agreement is found, while stations in the eastern Mediterranean region and 


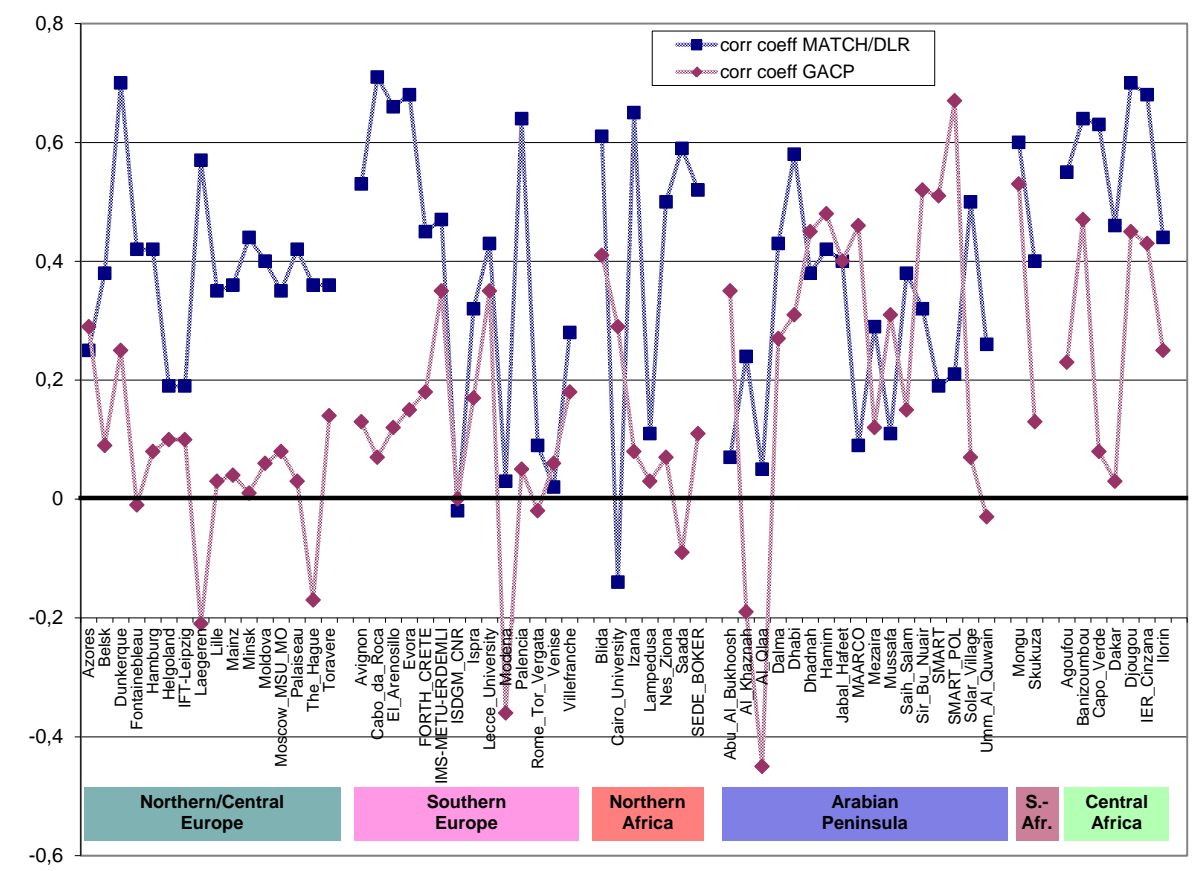

Fig. 10. Correlation coefficients for GACP (diamond) and daily mean MATCH/DLR (square) AOD values evaluated at AERONET stations. Stations are grouped according to regions as defined in Fig. 1.

Italy frequently show also a peak-like overestimation in the dust component. This occurs also on the Arabian Peninsula, but is not observed at the Central African stations - these tend to underestimate at some locations. Case studies show that these overestimations result from cloud systems with dust uptake. The regional dependency of overestimations and the lack of such effects in other regions like Central Africa point towards deficiencies in the underlying erodibility databases.

A post processing is empirically developed based on 2003 data to detect and eliminate these peak-like overestimations automatically. Suspicious dust events are removed if a strong temporal gradient in the dust component from day to day above 0.7 is observed or if the AOD value is above 1.0 with at least a $95 \%$ dust contribution. Flagged values are replaced by linearly interpolated values and finally, a 3 days low pass filter is applied. Extreme outliers are filtered out by this empirical procedure, but it has to be noted that dust events are replaced by low aerosol conditions. From the perspective of the solar sector being mainly interested in accurate values after such a cloudy period this is justified, but it is not appropriate for aerosol research especially in any dust mobilisation or aerosol-cloud interaction studies. In the Mediterranean, several stations in dust regions show a positive impact in cloud-free situations as validated with AERONET measurements, while other stations are less influenced. On the Arabian Peninsula and in Northern Africa, a positive impact can be observed at all stations. Frequently, AERONET data is missing due to the cloud-clearing scheme on those days with eliminated peaks. It can be speculated, that these peaks are realistic dust events in mixed dust/cloud conditions leading to a removal of the AERONET measurement by its own cloud detection. Such problems are well known for AERONET measurements and dust validation studies and restrict the assessment of the exact amplitude of the dust peak itself in MATCH. Nevertheless, the remaining data after such events suggest that the peak amplitude is typically modelled too high or that the deposition after the event is modelled to low.

In terms of RMSE the comparison of daily mean vs. hourly resolved modelling from nowadays state-of-the-art global modelling does not justify the use of an hourly resolved aerosol auxiliary dataset for solar energy applications. Nevertheless, it is assumed that more accurate daily means are obtained if the underlying dataset has a higher temporal resolution. This finding might change in future as a result of improvements of global aerosol modelling e.g., for dust parameterisations, emission databases and data assimilation efforts currently on-going.

The MATCH model is evaluated also against the GACP database as the currently used aerosol climatology in many solar databases. Especially, the correlation coefficient of daily mean MATCH/DLR is significantly higher than for the GACP dataset quantifying the expected value higher resolved aerosol data. Correlation coefficients above 0.7 are reached frequently while the use of a climatology results in much lower or even negative correlation coefficients at most stations. Nevertheless, it has to be noted that even if correlation coefficients are clearly increased by using a daily resolved 
dataset, they are still far from being sufficient. For many stations a linear correlation between modelled and observed values cannot be assumed - resulting in values of the correlation around 0.4 and at its maximum around 0.7 . Some stations even show correlation coefficients below 0.1 or even negative.

It has to be noted that the solar energy community requires bias-free information together with a correct frequency distribution of hourly AOD in order to derive proper frequency distributions of irradiances. The accuracy of the individual hourly AOD value is less important in assessments of historical irradiance data for power plant site selection and design as long as the frequency distribution is met successfully. Therefore, any increased modelling capability of the observed variance is welcome.

The MATCH/DLR dataset is currently under implementation for the SOLEMI irradiance processor which is a part of the European Commission's Global Monitoring for Environment and Security (GMES) programme. Finally, it can be concluded that several regions are modelled with a sufficient accuracy, while further investigations on dust emission schemes are recommended to increase the data quality on the Arabian Peninsula and for some Northern African stations.

Acknowledgements. Our thanks for the provision of ground measurements go to Ana Maria Silva, Anatoli Chaikovsky, Andrew Clive Banks, Arnon Karnieli, Bertil Hakansson, Brent Holben, Christoph Kleefeld, Christophe Francois, Didier Tanré, Gian Paolo Gobbi, Gilbert Sappe, Giuseppe Zibordi, Hammad BenChekroun, Jean-Francois Leon, Jens Boesenberg, Kevin Ruddick, Luigi Alberotanza, Maria Rita Perrone, Natalia Chubarova, Olavi Kärner, Paulo Artaxo, Peter Koepke, Philippe Goloub, Rachel T. Pinker, Roland Doerffer, Serge Despiau, Sergio Pugnaghi, Spyros Rapsomanikis, and Victoria E. Cachorro Revilla for their AERONET measurements. This work has been partly supported by the national projects SESK (Standardisation of energy yield assessments for solar thermal power plants) and Solar-MedAtlas funded by the Federal Ministry for the Environment, Nature Conservation and Nuclear Safety in Germany (contracts 0325084 A and 101 130) and extended during the EU Seventh Research Framework Programme's project MACC (Monitoring Atmospheric Composition and Climate) under contract 218793.

Edited by: E. Vignati

\section{References}

Anderson, T. L., Charlson, R. J., Winker, D. M., Ogren, J. A., and Holmen, K.: Mesoscale Variations of Tropospheric Aerosols, J. Atmos. Sci., 60, 119-136, 2003.

Barth, M. C., Rasch, P. J., Kiehl, J. T., Benkovitz, C. M., and Schwartz, S. E.: Sulfur chemistry in the National Center of Atmospheric Research Community climate Model: Description, evaluation, features and sensitivity to aqueous chemistry, J. Geophys. Res., 105, 1387-1415, 2000.
Benkovitz, C. M., Scholtz, M. T., Pacyna, J., Tarrason, L., Dignon, J., Voldner, E. C., Spiro, P. A., Logan, J. A., and Graedel, T. E.: Global gridded inventories of anthropogenic emissions of sulfur and nitrogen, J. Geophys. Res., 101, 29239-29253, 1996.

Beyer, H.-G., Costanzo, C., and Heinemann, D.: Modifications of the Heliosat procedure for irradiance estimates from satellite images, Solar Energy, 56, 207-212, 1996.

Blanchard, D. C. and Woodcook, A. H.: Production, concentration, and vertical distribution of the sea salt aerosol, Ann. New York Acad. Sci., 338, 330-347, 1980.

Cano, D., Monget, J., Albuisson, M., Guillard, H., Regas, N., and Wald, L.: A method for the determination of the global solar radiation from meteorological satellite data, Solar Energy, 37, 31-39, 1986.

Chin, M., Ginoux, P., Kinne, S., Torres, O., Holben, B. N., Duncan, B. N., Martin, R. V., Logan, J. A., Higurashi, A., and Nakajima, T.: Tropospheric aerosol optical thickness from the GOCART model and comparisons with satellite and sun photometer measurements, J. Atmos. Sci., 59, 461-483, 2002.

Collins, W. D., Rasch, P. J., Eaton, B. E., Khattatov, B. V., and Lamarque, J. F.: Simulating aerosols using a chemical transport model with assimilation of satellite aerosol retrievals: Methodology for INDOEX, J. Geophys. Res., 106, 7313-7336, 2001.

Dubovik, O., Holben, B., Eck, T. F., Smirnov, A., Kaufmann, Y. J., King, M. D., Tanré, D., and Slutsker, I.: Variability of Absorption and Optical Properties of Key Aerosol Types Observed in Worldwide Locations, J. Atmos. Sci., 59, 590-608, 2002.

Fillmore, D. W.: Anthropogenic Aerosols and the Scattering and Absorption of Solar Radiation - Estimates of the Climatic Impacts through a Synthesis of Models and Satellite Observations, PhD Thesis, University of Colorado, USA, 2005.

Ginoux, P., Chin, M., Tegen, I., Prospero, J. M., Holben, B., Dubovik, O., and Lin, S.-J.: Sources and distributions of dust aerosols simulated with the GOCART model, J. Geophys. Res., 106, 20255-20273, 2001.

Gong, S. L. and Zhang, X. Y.: CUACE/Dust - an integrated system of observation and modelling systems for operational dust forecasting in Asia, Atmos. Chem. Phys., 8, 2333-2340, doi:10.5194/acp-8-2333-2008, 2008.

Guenther, A., Hewitt, C. N., Erickson, D., Fall, R., Geron, C., Graedel, T., Harley, P., Klinger, L., Lerdau, M., Mckay, W. A., Pierce, T., Scholes, B., Steinbrecher, R., Tallamraju, R., Taylor, J., and Zimmerman, P.: A global model of natural volatile organic compound emissions, J. Geophys. Res., 100, 8873-8892, 1995.

Hand, J. L., Mahowald, N. M., Chen, Y., Siefert, R. L., Luo, C., Subramaniam, A., and Fung, I: Estimates of atmosphericprocessed soluble iron from observations and a global mineral aerosol model: Biogeochemical implications, J. Geophys. Res., 109, D17205, doi:10.1029/2004JD004574, 2004.

Haywood, J. M. and Ramaswamy, V.: Global sensitivity studies of the direct radiative forcing due to anthropogenic sulfate and black carbon aerosols, J. Geophys. Res., 103, 6043-6058, 1998.

Heinold, B., Tegen, I., Esselborn, M., Kandler, K., Knippertz, P., Müller, D., Schladitz, D., Tesche, M., Weinzierl, B., Ansmann, Al., Althausen, D., Laurent, B., Massling, A., Müller, T., Petzold, A., Schepanski, K., and Wiedensohler, A.: Regional Saharan dust modelling during the SAMUM 2006 campaign, Tellus, 61B, 307-324, 2009. 
Holben, B. N., Eck, T. F., Slutsker, I., Tanré, D., Buis, J. P., Setzer, A., Vermote, E., Reagan, J. A., Kaufmann, Y. J., Nakajima, T., Lavenu, F., Jankowiak, I., and Smirnov, A.: AERONET: A federated instrument network and data archive for aerosol characterisation, Remote Sens. Environ., 66, 1-16, 1998.

Huneeus, N., Schulz, M., Balkanski, Y., Griesfeller, J., Prospero, J., Kinne, S., Bauer, S., Boucher, O., Chin, M., Dentener, F., Diehl, T., Easter, R., Fillmore, D., Ghan, S., Ginoux, P., Grini, A., Horowitz, L., Koch, D., Krol, M. C., Landing, W., Liu, X., Mahowald, N., Miller, R., Morcrette, J.-J., Myhre, G., Penner, J., Perlwitz, J., Stier, P., Takemura, T., and Zender, C. S.: Global dust model intercomparison in AeroCom phase I, Atmos. Chem. Phys., 11, 7781-7816, doi:10.5194/acp-11-7781-2011, 2011.

IEA - International Energy Agency/Organization for Economic Cooperation and Development: Energy Statistics and Balances, diskette service, 1997.

Jolliff, J. K., Kindle, J. C., Shulman, I., Penta, B., Friedrichs, M. A. M., Helber, R., and Arnone, R. A.: Summary diagrams for coupled hydrodynamic-ecosystem model skill assessment, J. Mar. Syst., 76, 64-82, 2009.

Kettle, A. J., Andreae, M. O., Amouroux, D., Andreae, T. W., Bates, T. S., Berresheim, H., Bingerner, H., Boniforti, R., Curran, M. A. J., DiTullio, G. R., Helas, G., Jones, G. B., Keller, M. D., Kiene, R. P., Leck, C., Levasseur, M., Malin, G., Maspero, M., Matrai, P., McTaggart, A. R., Mihalopoulous, N., Nguyen, B. C., Novo, A., Putaud, J. P., Rapsomanikis, S., Roberts, G., Schebeske, G., Sharma, S., Simó, R., Staubes, R., Turner, S., and Uher, G.: A global database of sea surface dimethylsulfide (DMS) measurements and a procedure to predict sea surface DMS as a function of latitude, longitude and month, Global Biogeochem. Cy., 13, 399-444, 1999.

Kiehl, J. T., Schneider, T. L., Rasch, P. J., Barth, M. C., and Wong, J.: Radiative forcing due to sulfate aerosols from simulations with the National Center for Atmospheric Research Community Climate Model, Version 3, J. Geophys. Res., 105, 1441-1457, 2000.

Kinne, S., Lohmann, U., Feichter, J., Schulz, M., Timmreck, C., Ghan, S., Easter, R., Chin, M., Ginoux, P., Takemura, T., Tegen, I., Koch, D., Herzog, M., Penner, J., Pitari, G., Holben, B., Eck, T., Smirnov, A., Dubovik, O., Slutsker, I., Tanre, D., Torres, O., Mishchenko, M., Geogdzhayev, I., Chu, D. A., and Kaufman, Y.: Monthly Averages of Aerosol Properties: A Global comparison among models, satellite data and AERONET ground data, J. Geophys. Res., 108, 4634, doi:10.1029/2001JD001253, 2003.

Kinne, S., Schulz, M., Textor, C., Guibert, S., Balkanski, Y., Bauer, S. E., Berntsen, T., Berglen, T. F., Boucher, O., Chin, M., Collins, W., Dentener, F., Diehl, T., Easter, R., Feichter, J., Fillmore, D., Ghan, S., Ginoux, P., Gong, S., Grini, A., Hendricks, J., Herzog, M., Horowitz, L., Isaksen, I., Iversen, T., Kirkevåg, A., Kloster, S., Koch, D., Kristjansson, J. E., Krol, M., Lauer, A., Lamarque, J. F., Lesins, G., Liu, X., Lohmann, U., Montanaro, V., Myhre, G., Penner, J., Pitari, G., Reddy, S., Seland, O., Stier, P., Takemura, T., and Tie, X.: An AeroCom initial assessment - optical properties in aerosol component modules of global models, Atmos. Chem. Phys., 6, 1815-1834, doi:10.5194/acp-6-1815-2006, 2006.

Liousse, C. J., Penner, J. E., Chunag, C., Walton, J. J., Eddleman, H., and Cachier, H.: A global three-dimensional model study of carbonaceous aerosols, J. Geophys. Res., 101, 19411-19432,
1996.

Luo, C., Mahowald, N. M., and del Corral, J.: Sensitivity study of meteorological parameters on mineral aerosol mobilization, transport, and distribution, J. Geophys. Res., 108, 4447, doi:10.1029/2003JD003483, 2003.

Mahowald, N. M., Rasch, P. J., Eaton, B. E., Whittlestone, S., and Prinn, R. G.: Transport of 222radon to the remote troposphere using the Model of Atmospheric Transport and Chemistry and assimilated winds from ECMWF and the National Center for Environmental Prediction/NCAR, J. Geophys. Res., 102, 2813928151, 1997.

Mahowald, N., Zender, C., Luo, C., Savoie, D., Torres, O., and del Corral, J.: Understanding the 30-year Barbados desert dust record, J. Geophys. Res., 107, 4561, doi:10.1029/2002JD002097, 2002.

Mahowald, N., Luo, C., del Corral, J., and Zender, C.: Interannual variability in atmospheric mineral aerosols from a 22-year model simulation and observational data, J. Geophys. Res., 108, 4352, doi:10.1029/2002JD002821, 2003.

Marticorena, B. and Bergametti, G.: Modeling the atmospheric dust cycle: 1 . Design of a soil-derived dust emission scheme, J. Geophys. Res., 100, 16415-16430, 1995.

Morcrette, J.-J., Boucher, O., Jones, L., Salmond, D., Bechthold, P., Beljaars, A., Benedetti, A., Bonet, A., Kaiser, J. W., Razinger, M., Schulz, M., Serrar, S., Simmons, A. J., Sofiev, M., Suttie, M., Tomplins, A. M., and Untch, A.: Aerosol analysis and forecast in the European Centre for Medium-Range Wweather Forecasts Integrated Forecast System: Forward modelling, J. Geophys. Res., 114, D06206, doi:10.1029/2008JD011235, 2009.

Olivier, J. G. J., Bouwman, A. F., Van der Maas, C. W. M., Berdowski, J. J. M., Veldt, C., Bloos, J. P. J., Visschedijk, A. J. H., Zandveld, P. Y. J., and Haverlag J. L.: Description of EDGAR Version 2.0, RIVM, Bilthoven, RIVM report nr. 771060 002/TNO MEP report nr. R96/119, 1996.

Patterson, E. M.: Optical properties of the crustal aerosol: Relation to chemical and physical characteristics, J. Geophys. Res., 86, 3236-3246, 1981.

Penner, J. E., Eddleman, J., and Novakov, T.: Towards the development of a global inventory for black carbon emissions, Atmos. Environ., 27, 1277-1295,1993.

Rasch, P. J. and Kristjansson, J. E.: A comparison of the CCM3 model climate using diagnosed and predicted condensate parameterizations, J. Clim., 11, 1587-1614, 1998.

Rasch, P. J. and Lawrence, M.: Recent development in transport methods at NCAR, Technical report, National Center for Atmospheric Research and Max Planck Institut für Chemie, 1998.

Rasch, P. J., Mahowald, N. M., and Eaton, B. E.: Representations of transport, convection, an the hydrologic cycle in chemical transport models: Implications for the modelling of short-lived and soluble species, J. Geophys. Res., 102, 28127-28138, 1997.

Rasch, P. J., Barth, M. C., Kiehl, J. T., Schwartz, S. E., and Benkovitz, C. M.: A description of the global sulfur cycle and its controlling processes in the National Center for Atmospheric Research Community climate Model, Version 3, J. Geophys. Res., 105, 1367-1385, 2000.

Reid, J. S., Piketz, S. J., Kahn, R., Bruintjes, R. T., and Holben, B. N.: A Summary of First Year Activities of the United Arab Emirates Unified Aerosol Experiment: UAE ${ }^{2}$, Naval Research Laboratory, Monterey, USA, report NRL/MR/7534-05-8899, 2005. 
Rhyaboshpako, A. G., Brukhanov, P. A., Gromov, S. A., Proshina, Y. V., and Aginogenova, O. G.: Anthropogenic emissions of oxidized sulfur and nitrogen into the atmosphere of the Former Soviet Union in 1985 and 1990, Department of Meteorology, Stockholm University, Report CM-89, 1996.

Rigollier C., Lefèvre, M., and Wald, L.: The method HELIOSAT2 for deriving shortwave solar radiation from satellite images, Solar Energy, 77, 159-169, 2004.

Santese, M., Perrone, M. R., Zakey, A. S., De Tomasi, F., and Giorgi, F.: Modeling of Saharan dust outbreaks over the Mediterranean by RegCM3: case studies, Atmos. Chem. Phys., 10, 133156, doi:10.5194/acp-10-133-2010, 2010.

Schillings, C., Mannstein, H., and Meyer, R.: Operational method for deriving high resolution direct normal irradiance from satellite data, Solar Energy, 76, 475-484, 2004.

Schmidt, G. A., Ruedy, R., and Hansen, J. E.: Present-day Atmospheric Simulations Using GISS ModelE: Comparison to In Situ, Satellite, and Reanalysis Data, J. Clim., 19, 153-192, 2006.

Smith, S. J., Pitcher, H., and Wigley, T. M. L.: Global and regional anthropogenic sulfur dioxide emissions, Glob. Biogeochem. Сy., 29, 99-119, 2001.

Spyrou, C., Mitsakou, C., Kallos, G., Louka, P., and Vlastou, G.: An improved limited area model for describing the dust cycle in the atmosphere, J. Geophys. Res., 115, D17211, doi:10.1029/2009JD013682, 2010.

Streets, D. G. and Waldhoff, S.: Biofuel use in Asia and acidifying emissions, Energy, 23, 1029-1042, 1998.

Su, L. and Toon, O. B.: Numerical simulations of Asian dust storms using a coupled climate-aerosol microphysical model, J. Geophys. Res., 114, D14202, doi:10.1029/2008JD010956, 2009.
Takemura, T., Nakajima, T., Dubovik, O., Holben, B. N., and Kinne, S.: Single-Scattering Albedo and Radiative Forcing of Various Aerosol Species with a global three-dimensional model, J. Clim., 4, 333-352, 2002.

Tegen, I., Hollring, P., Chin, M., Fung, I., Jacob, D., and Penner, J.: Contribution of different aerosol species to the global aerosol extinction optical thickness: Estimates from model results, J. Geophys. Res., 102, 23895-23915, 1997.

Textor, C., Schulz, M., Guibert, S., Kinne, S., Balkanski, Y., Bauer, S., Berntsen, T., Berglen, T., Boucher, O., Chin, M., Dentener, F., Diehl, T., Easter, R., Feichter, H., Fillmore, D., Ghan, S., Ginoux, P., Gong, S., Grini, A., Hendricks, J., Horowitz, L., Huang, P., Isaksen, I., Iversen, I., Kloster, S., Koch, D., Kirkevåg, A., Kristjansson, J. E., Krol, M., Lauer, A., Lamarque, J. F., Liu, X., Montanaro, V., Myhre, G., Penner, J., Pitari, G., Reddy, S., Seland, Ø., Stier, P., Takemura, T., and Tie, X.: Analysis and quantification of the diversities of aerosol life cycles within AeroCom, Atmos. Chem. Phys., 6, 1777-1813, doi:10.5194/acp-6-1777-2006, 2006.

Wittmann, M., Breitkreuz, H., Schroedter-Homscheidt, M., and Eck, M.: Case Studies on the Use of Solar Irradiance Forecast for Optimized Operation Strategies of Solar Thermal Power Plants, IEEE Journal of Selected Topics in Applied Earth Observations and Remote Sensing, 1, 18-27, doi:10.1109/JSTARS.2008.2001152, 2008.

Zender, C. S., Bian, H., and Newman, D.: Mineral Dust Entrainment and Deposition (DEAD) model: Description and 1990s dust climatology, J. Geophys. Res., 108, 4416-4434, 2003. 